\title{
VALIDITY OF ASTHMA CONTROL TEST \\ IN ASSESSING ASTHMA CONTROL IN CZECH OUTPATIENT SETTING
}

\author{
Elena Gurková1, Patrice Popelková2 \\ ${ }^{1}$ Department of Nursing, Faculty of Health Care, University of Presov, Presov, Slovak Republic \\ ${ }^{2}$ Department of Nursing and Midwifery, Faculty of Medicine, University of Ostrava, Ostrava, Czech Republic
}

\section{SUMMARY}

Aim: The aim of the study was to determine the reliability and validity of the agreement between the Asthma Control Test (ACT) and Global Initiative for Asthma (GINA) in classifying asthma control in the Czech Republic.

Methods: A sample of 316 people with asthma was recruited from the Clinic of Tuberculosis and Respiratory Diseases of the University Hospital in Ostrava between November 2011 and July 2012. Two questionnaires were used in this study, the Asthma Control Test and Mini Asthma Quality of Life Questionnaire (Mini-AQLQ). Regardless of the questionnaire results the asthma specialist assessed the asthma control status of enlisted patients according to the criteria described in the GINA 2006 guidelines.

Results: The internal consistency of the five-item ACT was good. The ACT score of $\geq 20$ predicted GINA-defined controlled asthma in $29 \%$ of cases with a sensitivity of $65 \%$ and specificity of $89 \%$. The kappa level of agreement between the ACT classification and GINA classification of asthma control was 0.29 , suggesting fair agreement. The ACT score showed the strongest correlation with the specialists' rating, followed by the $\mathrm{FEV}_{1}$ percent predicted. Overall, in line with previous studies we confirmed significant relationship between the ACT scores and FEV and health related quality of life.

Conclusions: ACT is a reliable and simple tool that might be a significant asset in the management of outpatients with asthma in the Czech Republic. The ACT score correlates well with lung function parameters and health related quality of life. It appears to be a good tool to predict GINA-defined 'not-controlled asthma.'

Key words: asthma control, asthma control test, GINA guidelines, Czech Republic

Address for correspondence: E. Gurková, Department of Nursing, Faculty of Health Care, University of Presov, Partizánska 1, 08001 Presov, Slovak Republic. E-mail: elena.gurkova@unipo.sk

\section{INTRODUCTION}

Asthma continues to be a major public health concern worldwide (1). In 2004, Masoli et al. (2) and the Global Initiative for Asthma (GINA) estimated the prevalence of current asthma symptoms in the Czech Republic to be $8 \%$ among adults (4). According to the World Health Survey (1) the prevalence rates of doctor diagnosed asthma, clinical/treated asthma and wheezing among adults in the Czech Republic were $4.5 \%, 4.7 \%$ and $6.3 \%$, respectively. Achieving asthma control remains an elusive goal for the majority of patients worldwide (3). Asthma control is a key component for asthma treatment and asthma management (4, 5). Current clinical guidelines (4-6) emphasise the importance of asthma control evaluation rather than asthma severity in order to guide asthma management decisions. Therefore, more recently, the multidimensional concept of asthma control has been introduced to better describe the status of disease after intervention $(7,8)$. Asthma control "is generally considered to reflect disease activity as captured by punctuations in symptoms and the degree to which these symptoms limit activities, disturb sleep or require the use of a rescue inhaler" (9). Controlled asthma is characterised by minimal or no symptoms during the day and at night, no asthma attacks, no emergency visits to physicians or hospitals, minimal need for relieve medications, no limitation on physical activities and exercises, nearly normal lung function, and minimal or no side-effects from medication (10). The Global Initiative for Asthma (4) defines asthma control as "no limitations of activities, no nocturnal symptoms, minimal or no daytime symptoms, minimal or no need for rescue therapy, normal lung function, and no exacerbations". Despite the ongoing development of improved treatments for asthma and the availability of regularly updated, evidence-based guidelines, large population-based studies (e.g. the International Asthma Patient Insight Research - INSPIRE study, the Asthma Insights and Reality in Central and Eastern Europe - AIRE study, the Reality of Asthma Control - TRAC study, etc.) report that a substantial portion of adults with asthma is not optimally controlled (10-13).

Several patient-centred methods have been developed to measure asthma control, such as the Asthma Control Questionnaire (ACQ), Asthma Control Test (ACT), Asthma Control Scoring System (ACSS), or Asthma Therapy Assessment Questionnaire (ATAQ) (14-17). An international panel of experts invited by the International Primary Care Respiratory Group (10) recommended ACT and ACQ as validated and reliable tools responsive to changes in asthma control over time. ACT provides a more simplified assessment of control by not requiring lung function assessments $(7,15,18,19)$ and by providing a meaningful and easy scoring method that is simpler than previous asthma ques- 
tionnaires and comprehensive enough to evaluate the range of asthma control (7). Moreover, it can be applied at all levels of healthcare $(7,15,18,19)$.

In the Czech Republic, the GINA guidelines are used as the main reference source for the national asthma guidelines. However, studies evaluating the level of asthma control in the Czech Republic are still rare. A simple, applicable, accessible and validated tool to assess asthma control is therefore needed for patients with asthma in the Czech Republic. ACT has been the recent and most commonly used complementary tool in assessing asthma control in the Czech Republic. However, this tool has not yet been validated as a reliable predictor of GINA-defined asthma control here. A study was therefore undertaken to validate the Czech version of ACT.

The objective was to determine the reliability and validity of the agreement between ACT and GINA in classifying asthma control and to identify major determinants of pure asthma control.

\section{Sample}

This was an observational study recruiting ambulatory patients with asthma at the Clinic of Respiratory Diseases and Tuberculosis of the University Hospital in Ostrava, Czech Republic between November 2011 and July 2012. Written informed consent was obtained from all ultimately selected patients.

Patients who passed the inclusion criteria ( $\geq 18$ years old, asthma diagnosed according to GINA during past 6 months, able to perform spirometry and complete the questionnaire) were included in the study. Subjects were excluded if they met any of the following exclusion criteria: presence of any comorbidity that could affect adversely quality of life (severe cardiac, hepatic, renal, psychiatric illness or pregnancy), presence of any respiratory disorder other than asthma (emphysema, bronchiectasis, bronchitis and tuberculosis). Patients who could not finish the lung function tests or complete the questionnaire were also excluded.

A total of 321 adult patients were invited to participate in the study, $316(98.4 \%)$ agreed to participate, $75 \%$ of them were females.

\section{MATERIALS AND METHODS}

\section{Questionnaires}

Two questionnaires were used in this study: the Asthma Control Test (15) and Mini Asthma Quality of Life Questionnaire (Mini-AQLQ) (20).

The Asthma Control Test, a validated 5-item self-administered survey designed to assess asthma control over previous four weeks, was administered to the subjects. ACT is scored on a scale from 5 to 25 with the higher scores reflective of better asthma control. The Mini-AQLQ Czech version was used with consent of authors of Mini-AQLQ. Linguistic validation of the Czech version has been done by the MAPI Research.

The 15-question Mini-AQLQ (20) is an asthma-specific quality-of-life questionnaire reflecting the prior 2 weeks, with a total score and 4 domain scores (symptom, emotion, activity, and environment), with each score ranging from 1 to 7 (higher scores indicate better quality of life).

\section{Rating by Asthma Specialist}

Eligible patients completed questionnaires (ACT and the Mini Asthma Quality of Life Questionnaire) during a routine, previously scheduled physician office visit. After each patient completed a survey, office staff recorded pre-bronchodilator measurements of $\mathrm{FEV}_{1}$, checked demonstration of the inhalation technique and the asthma specialist, regardless of each subject's survey responses, interviewed the patient and provided treatment modifications as required.

According to the results of rating by the specialist, the patient's asthma was classified as uncontrolled, partly controlled or controlled. Based on the GINA 2006 guidelines $(4,6)$, the following items were evaluated in each patient: the severity of asthma (classified as mild intermittent asthma, mild persistent asthma, moderate persistent asthma or severe persistent asthma), asthma control level scored according to a 3-point scale (uncontrolled asthma, partly controlled asthma or controlled asthma), and the necessity of treatment adjustment (stepping down, no change, stepping up). Spirometry was performed using ZAN 100 Handy USB device.

\section{Statistical Analysis}

A statistical analysis was performed with Statistical Package for the Social Sciences 15.0 (SPSS, Inc., Chicago, IL, USA). A p-value 0.05 was taken to indicate statistical significance for all comparisons.

\section{Reliability}

Cronbach's alpha was used to determine the internal reliability of 5 items of the ACT questionnaire $(7,15,18,19)$.

\section{Empirical Validation}

First, correlation analyses were calculated between ACT scores, the specialist rating of control, and the percentage of forced expiratory volume in 1 second $\left(\% \mathrm{FEV}_{1}\right)$ compared with the predicted value and asthma-specific quality of life. The relationship between results of the ACT classification and GINA classification (between two ordinal variables) was determined by the Spearman's rank correlation coefficients (r). The relationship between ACT and the percentage of forced expiratory volume in 1 second $\left(\% \mathrm{FEV}_{1}\right)$, compared with the predicted value, was determined by Pearson's correlation coefficients (r). Convergent validity of ACT was tested by correlations of ACT with the total and domain scores of Mini-AQLQ. Second, evidence for construct validity (known groups approach) was provided by the relationship between the ACT scores and other clinical variables. We hypothesized that the groups of patients classified as in "better" control according to the specialist's rating and as determined by percent predicted $\mathrm{FEV}_{1}$ would score higher on ACT than the groups of patients classified as having little or no control. Differences in ACT scores among the groups with different $\mathrm{FEV}_{1}$ percent predicted values, and specialists' ratings were evaluated with analysis of variance. For group comparisons, one way ANOVA, Fisher's least significant difference (LSD), Kruskal-Wallis test and Pearson's chi-square test were performed where appropriate. 


\section{Sensitivity and Specificity of ACT as a Screening Tool in Assessing Asthma Control}

The sensitivity, specificity, positive predictive value, negative predictive value, and the percentage of patients correctly classified was calculated using each ACT score as the cut-off point for GINA-defined controlled asthma (18). Sensitivity was defined as the percentage of patients with GINA-defined partly controlled/ uncontrolled asthma identified correctly by ACT. Specificity was defined as the percentage of patients with GINA-defined controlled asthma identified correctly by ACT. Positive predictive value (PPV) was the percentage of patients to whom ACT predicted correctly to have partly controlled/uncontrolled asthma. Negative predictive value (NPV) was the percentage of patients to whom ACT predicted correctly to have controlled asthma (18). In the ternary split of GINA-defined asthma control, the agreement between GINA rating (uncontrolled, partly controlled and controlled asthma) and ACT rating (ACT score < 15, 15-19 and 20-25) in the classification of asthma control was determined using the kappa coefficient of agreement and correctly classified rates (19).

\section{RESULTS}

Descriptive characteristics of the sample are summarized in Table 1. The mean percentage of predicted $\mathrm{FEV}_{1}$ was 77.27 $(\mathrm{SD} \pm 21.92)$ and the mean ACT was $17.58(\mathrm{SD} \pm 5.48)$. The majority of patients had uncontrolled $(59.9 \%)$ or partly controlled (32\%) asthma according to the ACT criteria. $29.7 \%$ of patients were current smokers, $20.6 \%$ were ex-smokers and $49.7 \%$ have never smoked. Surprisingly, only $3.1 \%$ of patients performed regular home self-monitoring of their peak expiratory flow (PEF), although $41.1 \%$ of them owned peak flow meter. Notable fact was that only $55.7 \%$ of patients used their inhaler properly.

According to the results of the specialists' rating (Table 1), the patients were classified into an uncontrolled group (34.5\%), partly controlled group $(51.3 \%)$ and controlled group (14.2\%). The three groups showed no significant differences in the distribution of gender $(p=0.33)$, smoking history $(p=0.23)$ or degree of performing home self-monitoring of PEF $(\mathrm{p}=0.11)$. The three groups showed significant differences in the distribution of age $(\mathrm{p}=0.03)$, asthma duration $(\mathrm{p}=0.04)$ and correct inhalation technique $(p<0.001)$. However, significant differences were found in the results of spirometry, ACT and Mini-AQLQ scores $(p<0.001)$. Patients with their asthma under control achieved FEV of $97.20 \% \pm 11.28 \%$ of predicted value, ACT score of $23.20 \pm 2.84$ and Mini-AQLQ score of $6.10 \pm 0.66$. Patients with their asthma under partial control achieved $\mathrm{FEV}_{1}$ of $78.81 \% \pm 20.62 \%$ of predicted value, ACT score of $19.28 \pm 4.33$ and Mini-AQLQ score of $5.07 \pm 1.07$. Patients with their asthma uncontrolled achieved FEV of $66.75 \% \pm 20.85 \%$ of predicted value, ACT score of $12.74 \pm 3.89$ and Mini-AQLQ score of $3.67 \pm 1.04$.

\section{Reliability and Empirical Validity of ACT}

The internal consistency of the five-item ACT was 0.87 in the total sample, suggesting high consistency among answers to the five questions of the ACT questionnaire. The ACT score showed strong correlation with the specialists' rating $(\mathrm{r}=0.646)$, followed by the $\mathrm{FEV}_{1}$ percent predicted $(\mathrm{r}=0.580)$. The correlation between
Table 1. Characteristic of the sample $(N=316)$

\begin{tabular}{|l|c|c|}
\hline Characteristic & $\mathbf{n}$ & $\%$ \\
\hline Asthma duration \\
\hline $0-5$ years & 88 & 27.8 \\
\hline $6-10$ years & 85 & 26.9 \\
\hline $11-15$ years & 65 & 20.6 \\
\hline$\geq 16$ years & 78 & 24.7 \\
\hline
\end{tabular}

\section{Asthma severity according to GINA}

\begin{tabular}{|l|c|c|}
\hline Stage 1 - intermittent & 25 & 7.9 \\
\hline Stage 2 - mild persistent & 138 & 43.7 \\
\hline Stage 3 - moderate persistent & 123 & 38.9 \\
\hline Stage 4 - severe persistent & 30 & 9.5 \\
\hline
\end{tabular}

Medication use before visit

\begin{tabular}{|l|c|c|}
\hline None & 117 & 37.0 \\
\hline SABA & 199 & 63.0 \\
\hline LABA & 29 & 9.2 \\
\hline ICS & 93 & 29.4 \\
\hline LABA and ICS & 187 & 59.2 \\
\hline Theophylline & 59 & 18.7 \\
\hline Leukotriene antagonists & 46 & 14.6 \\
\hline Relief therapy & 101 & 32.0 \\
\hline
\end{tabular}

Inhalation technique

\begin{tabular}{|l|l|l|}
\hline Good & 176 & 55.7 \\
\hline Incorrect & 140 & 44.3 \\
\hline
\end{tabular}

Self-monitoring of PEF

\begin{tabular}{|l|c|c|}
\hline Regular self-monitoring of PEF & 10 & 3.1 \\
\hline Irregular self-monitoring of PEF & 120 & 48.0 \\
\hline Patients without peak flow meter & 186 & 58.9 \\
\hline
\end{tabular}

$\mathrm{FEV}_{1} \%$ of predicted value

\begin{tabular}{|l|c|c|}
\hline $0-44 \%$ & 28 & 8.9 \\
\hline $45-59 \%$ & 35 & 11.1 \\
\hline $60-79 \%$ & 101 & 32.0 \\
\hline $80 \%$ & 152 & 48.1 \\
\hline
\end{tabular}

Asthma control

GINA classification

\begin{tabular}{|l|c|c|}
\hline Uncontrolled & 109 & 34.5 \\
\hline Partially controlled & 162 & 51.3 \\
\hline Controlled & 45 & 14.2 \\
\hline
\end{tabular}

ACT classification

\begin{tabular}{|l|c|c|}
\hline Uncontrolled & 180 & 59.9 \\
\hline Partially controlled & 101 & 32.0 \\
\hline Controlled & 35 & 11.1 \\
\hline
\end{tabular}

ACT - Asthma control test, $\mathrm{FEV}_{1}$ - forced expiratory volume in 1 second, GINA - Global Initiative for Asthma, ICS - Inhaled corticosteroid, LABA - Long-acting beta2-agonist, $\mathrm{n}$ - number of patients, PEF - Peak expiratory flow, SABA Short-acting beta2-agonist

the specialists' rating of asthma control and $\mathrm{FEV}_{1}(\mathrm{r}=0.443)$ was moderate. Strong associations were found between the ACT score and health related quality of life (HRQoL) operationalized 
by the overall Mini-AQLQ score $(\mathrm{r}=0.839)$. The strongest correlation was found between symptoms domain of Mini-AQLQ $(r=0.859)$, followed by activity domain $(r=0.767)$, emotion domain $(r=0.689)$, and the environment domain $(r=0.589)$. Positive relationship was also found between the overall Mini-AQLQ score and the relative $\mathrm{FEV}_{1}(\mathrm{r}=0.429)$.

Mean ACT scores differed significantly across the groups of patients who differed in level of asthma control defined by the specialist's rating of control and by percent predicted $\mathrm{FEV}_{1}$ levels. The mean ACT score of the controlled group was sig- nificantly higher than those of the partly controlled group and uncontrolled group $(\mathrm{F}-\mathrm{ratio} / \mathrm{F}=138.55 ; \mathrm{dft} /$ total variance $=315$, $\mathrm{dfb} /$ between-group variance $=2, \mathrm{dfw} /$ within-group variance $=$ 313, $\mathrm{p}<0.001$ ). Mean ACT scores differed significantly across the groups of patients who differed in percent predicted $\mathrm{FEV}_{1}$ levels. Patients were categorized into 4 groups according to their $\mathrm{FEV}_{1}$ values (Table 1). There were significant differences in ACT score between these 4 groups (F-ratio/F $=30.68$; dft/ total variance $=315, \mathrm{dfb} /$ between-group variance $=3, \mathrm{dfw} /$ within-group variance $=312, \mathrm{p}<0.001)$.

Table 2. Performance of ACT score at different cut-off points in predicting GINA categories of asthma control (controlled versus partly controlled/uncontrolled) for the sample $(N=316$, all data are percentages)

\begin{tabular}{|c|c|c|c|c|c|}
\hline ACT score cut-off & Sensitivity & Specificity & Correctly classified & $\begin{array}{c}\text { Positive predictive } \\
\text { value }\end{array}$ & $\begin{array}{l}\text { Negative predictive } \\
\text { value }\end{array}$ \\
\hline$\geq 5$ & 0 & 100 & 14 & - & 14 \\
\hline$\geq 6$ & 1 & 100 & 15 & 100 & 14 \\
\hline$\geq 7$ & 3 & 100 & 16 & 100 & 15 \\
\hline$\geq 8$ & 4 & 100 & 17 & 100 & 15 \\
\hline$\geq 9$ & 7 & 100 & 21 & 100 & 15 \\
\hline$\geq 10$ & 11 & 100 & 23 & 100 & 16 \\
\hline$\geq 11$ & 15 & 100 & 28 & 100 & 16 \\
\hline$\geq 12$ & 18 & 100 & 30 & 100 & 17 \\
\hline$\geq 13$ & 24 & 100 & 35 & 100 & 18 \\
\hline$\geq 14$ & 30 & 98 & 39 & 99 & 19 \\
\hline$\geq 15$ & 37 & 98 & 45 & 99 & 20 \\
\hline$\geq 16$ & 44 & 96 & 51 & 98 & 22 \\
\hline$\geq 17$ & 48 & 93 & 54 & 98 & 23 \\
\hline$\geq 18$ & 53 & 93 & 59 & 98 & 25 \\
\hline$\geq 19$ & 59 & 93 & 64 & 98 & 28 \\
\hline$\geq 20$ & 65 & 89 & 68 & 97 & 29 \\
\hline$\geq 21$ & 72 & 87 & 74 & 97 & 34 \\
\hline$\geq 22$ & 77 & 84 & 78 & 97 & 38 \\
\hline$\geq 23$ & 83 & 76 & 82 & 95 & 43 \\
\hline$\geq 24$ & 89 & 64 & 85 & 94 & 49 \\
\hline$\geq 25$ & 95 & 49 & 89 & 92 & 63 \\
\hline
\end{tabular}

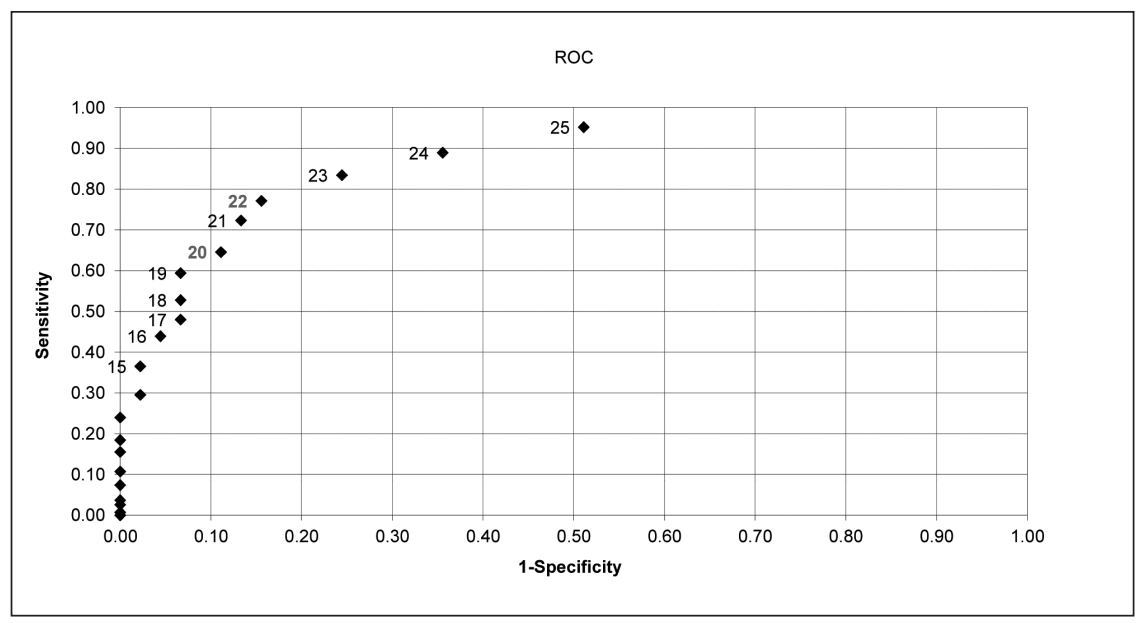

Fig. 1. Receiver operating characteristics - ROC curve of the ACT for assessing controlled asthma; - cut-off points. 


\section{Sensitivity and Specificity of ACT as a Screening Tool in Assessing Asthma Control}

Table 2 includes the positive and negative predictive values as well as sensitivity and specificity of the ACT score at different cut-off points. With the cut-off point of $\geq 20$ for the ACT score defining well-controlled asthma, a sensitivity of the ACT score was $65 \%$, specificity $89 \%$, PPV $97 \%$, and NPV $29 \%$ (Table 2, Fig. 1). The ACT score of $\geq 20$ predicted GINA-defined controlled asthma in $29 \%$ of cases. With the cut-off point of $\geq 20$ for the ACT score defining well-controlled asthma, and a binary split for GINA classification (partly controlled/uncontrolled versus controlled asthma), the ACT score of $\leq 19$ (not well-controlled asthma) correctly predicted GINA-defined partly controlled/ uncontrolled asthma in $97 \%$ of cases. Using the cut-off point of $\geq 20$ for ACT well-controlled asthma, the kappa level of agreement was 0.29 , suggesting fair agreement. These characteristics indicate a good screening tool.

\section{DISCUSSION}

The majority of patients in our sample had uncontrolled (57\%) or partly controlled (32\%) asthma according to the ACT criteria. The International Primary Care Respiratory Group (IPCRG) (3, 10) focused on the analysis of reasons for poor asthma control and developed a consensus on how to improve the delivery of asthma care in the primary care settings, where most patients with asthma are followed up. The discussions centered arround understanding the patient's perspective as a means of improving asthma control $(3,10)$. Authors reported several clinical and behavioural determinants of asthma control. The level of asthma control achieved reflects the behaviour of both healthcare professionals and patients (10). As the important clinical factors were analysed the genetic characteristics of the individual, type of asthma, co-morbidity (e.g. dysfunctional breathing, allergic rhinitis), individual variation in response to treatment, incorrect choice of inhaler, poor technique, etc. (3). As the main patient-related determinants of asthma control were identified behavioural factors - smoking, including relative corticosteroid resistance among smokers with asthma (3); low patient expectations, aspirations and goals; patient adherence to treatment and other aspects of self-management; patients' common-sense beliefs about treatment and perceptions of asthma (10). There was low compliance in regular PEF selfmonitoring in our sample. Patients in the uncontrolled and partly controlled group performed more frequently incorrect inhaler technique. $64.9 \%$ of patients needed frequent education because of their poor inhalation technique. Poor inhalation technique is a common problem among patients with asthma, and asthma control worsens as the number of mistakes in technique increases (3). Poor inhalation technique and low compliance in regular home self-monitoring of PEF may be dominant factors contributing to suboptimal asthma control.

These partial results of the study confirmed a reciprocal relationship between subjective measures represented by healthrelated quality of life, perceived asthma control and objective indicators of disease (the GINA classification of asthma control, $\mathrm{FEV}_{1}$ ). The higher level of FEV ${ }_{1}$ and better asthma control contributed to higher health-related quality of life. These results are consistent with results of previous studies $(21,22)$ that observed a strong correlation between asthma control and quality of life.

ACT has been shown to be a reliable tool by previous studies $(7,15,18,19)$ and this is also confirmed by this study in a Czech outpatient setting in which Cronbach's alpha reached 0.87, indicating a high consistency among the answers to the five ACT questions. The ACT score $\leq 19$ was confirmed in previous studies $(7,18,19)$ as useful threshold for identifying patients with poorly controlled asthma as defined by GINA. The ACT score of $\geq 20$ predicted GINA-defined controlled asthma in $29 \%$ of cases with a sensitivity of $65 \%$ and specificity of $89 \%$. The sensitivity is similar to studies from other countries (18). Thomas et al. (18) in their cross-sectional survey compared the ACT score and GINA classification of asthma control among 2,949 patients attending primary care physicians and specialists in France, Germany, Italy, Spain, the UK, and the USA. They observed that the ACT score $\geq 20$ predicted GINA-defined controlled asthma in $51 \%$ of cases the time, and the kappa statistic $(0.42)$ suggested a moderate agreement using the cut-off point of $\geq 20$ for 'well controlled' asthma. The kappa level of agreement between the ACT classification and GINA classification of asthma control presented in several studies $(18,19)$ indicate moderate agreement between these two rating systems. In contrast with the previous studies, we found lower PPV and the kappa statistic. Discrepancies between the ACT classification and GINA classification of asthma control could be explained by variability in item content and grading between the

Table 3. Agreement between GINA classification and ACT classification of asthma control $(N=316)$

\begin{tabular}{|l|c|c|c|c|}
\hline \multirow{2}{*}{} & \multicolumn{3}{|c|}{ GINA-defined control } & Total \\
\cline { 2 - 5 } & $\begin{array}{c}\text { uncontrolled } \\
\mathbf{n}(\%)\end{array}$ & $\begin{array}{c}\text { partly controlled } \\
\mathbf{n}(\%)\end{array}$ & $\begin{array}{c}\text { controlled } \\
\mathbf{n}(\%)\end{array}$ \\
\hline $\begin{array}{l}\text { ACT<15 } \\
\text { (uncontrolled) }\end{array}$ & $73(23.1)$ & $26(8.2)$ & $3(1.0)$ & $100(32.3)$ \\
\hline $\begin{array}{l}\text { ACT 15-19 } \\
\text { partly controlled }\end{array}$ & $31(9.8)$ & $45(14.2)$ & $4(1.2)$ & $80(25.2)$ \\
\hline $\begin{array}{l}\text { ACT } \geq 20 \\
\text { controlled }\end{array}$ & $5(1.5)$ & $91(28.7)$ & $40(12.6)$ & $136(43.8)$ \\
\hline $\begin{array}{l}\text { Total } \\
n(\%)\end{array}$ & $109(34.4) \quad 162(51.1)$ & $45(14.7)$ & $316(100)$ \\
\hline
\end{tabular}

The kappa relates to using the cut-off point of $\geq 20$ on ACT 
ACT and GINA definitions (18). Overall, in line with previous studies $(19,21,22,23)$ we confirmed significant relationship between the ACT scores, FEV $_{1}$ and HRQoL. Consistently with the studies $(21,24)$ we also observed a greater correlation of ACT scores than spirometry with the specialist's rating.

This study has several limitations, including the possibility of patient selection bias as participants represent a strictly selected sample from a university hospital that may not be representative of the overall population of outpatients with asthma in the Czech Republic or asthma patients in primary health care. In spite of these limitations, our study indicates that ACT can be used as a reliable tool for routine asthma control evaluation in Czech primary healthcare facilities. As one of the barriers to asthma control assessment is the absence of spirometer in many clinical settings $(19,21,24)$. General practitioners in primary settings can use ACT instead of it $(19,24)$. Despite the efficacy of such procedure, its effectiveness should be verified in actual primary health conditions to ensure comparable level of correlation among parameters.

\section{CONCLUSION}

This is the first validation study of ACT undertaken in the Czech Republic. We have confirmed association between the ACT and GINA classification of asthma control, $\mathrm{FEV}_{1}$ and HRQoL. In summary, this study provides reliability and validation information regarding ACT in the Czech Republic. ACT is a reliable and simple tool that might be significant asset in the management of outpatients with asthma in the Czech Republic.

\section{Acknowledgements}

Thanks to Elisabeth Juniper for consent with the use of Mini-AQLQ. The study was supported by the Research Student Project SGS13/LF/2013 from University of Ostrava.

\section{Ethical Approval}

The study was approved by the Ethics Committee of the University Hospital in Ostrava.

\section{Conflict of Interests}

None declared

\section{REFERENCES}

1. To T, Stanojevic S, Moores G, Gershon AS, Bateman ED, Cruz AA, et al. Global asthma prevalence in adults: findings from the cross-sectional world health survey. BMC Public Health. 2012 Mar 19;12:204.

2. Masoli M, Fabian D, Holt S, Beasley R. Global Burden of Asthma: developed for the global initiative for asthma [Internet]. Wellington: Medical Research Institute of New Zealand; 2004 [cited 2013 Jun 27]. Available from: http://www.ginasthma.org/documents/8.

3. Haughney J, Price D, Kaplan A, Chrystyn H, Horne R, May N, et al. Achieving asthma control in practice: understanding the reasons for poor control. Respir Med. 2008 Dec;102(12):1681-93.

4. Global strategy for asthma management and prevention. Updated 2012 [Internet]. Global initiative for asthma (GINA); 2012 [cited 2013 Jun 27]. Available from: http://ginasthma.org.

5. National Heart, Lung, and Blood Institute. National Asthma Education Program. Expert Panel on the Management of Asthma. Expert Panel Report 3: Guidelines for the Diagnosis and Management of Asthma: Full Report 2007 [Internet]. Washington, D.C.: US Department of Health and
Human Services; 2007 [cited 2013 Jun 28]. Available from: http://www. nhlbi.nih.gov/guidelines/asthma/asthgdln.htm.

6. Global strategy for asthma management and prevention. Updated 2006 [Internet]. Global initiative for asthma (GINA); 2007 [cited 2013 Jul 12]. Available from: http://ginasthma.org.

7. Mendoza MM, Ong-Dela Cruz B, Guzman-Banzon AV, Ayuyao FG, De Guia TS. Comparative assessment of asthma control test (ACT) and GINA classification including FEV1 in predicting asthma severity. Phil Heart Center J. 2007;13(2):149-154.

8. Gandhi PK, Kenzik KM, Thompson LA, DeWalt DA, Revicki DA, Shenkman EA, et al. Exploring factors influencing asthma control and asthma-specific health-related quality of life among children. Respir Res. 2013 Feb 23;14:26.

9. Chen H, Gould MK, Blanc PD, Miller DP, Kamath TV, Lee JH, et al; TENOR Study Group. Asthma control, severity, and quality of life: quantifying the effect of uncontrolled disease. J Allergy Clin Immunol. 2007 Aug; 120(2):396-402.

10. Horne R, Price D, Cleland J, Costa R, Covey D, Gruffydd-Jones K, et al. Can asthma control be improved by understanding the patient's perspective? BMC Pulm Med. 2007 May 22;7:8.

11. Rabe KF, Vermeire PA, Soriano JB, Maier WC. Clinical management of asthma in 1999: the Asthma Insights and Reality in Europe (AIRE) study. Eur Respir J. 2000 Nov;16(5):802-7.

12. FitzGerald JM, Boulet LP, McIvor RA, Zimmerman S, Chapman KR. Asthma control in Canada remains suboptimal: the Reality of Asthma Control (TRAC) study. Can Respir J. 2006 Jul-Aug;13(5):253-9.

13. Koolen BB, Pijnenburg MW, Brackel HJ, Landstra AM, van den Berg NJ, Merkus PJ, et al. Comparing Global Initiative for Asthma (GINA) criteria with the Childhood Asthma Control Test (C-ACT) and Asthma Control Test (ACT). Eur Respir J. 2011 Sep;38(3):561-6.

14. Juniper EF, O'Byrne PM, Guyatt GH, Ferrie PJ, King DR. Development and validation of a questionnaire to measure asthma control. Eur Respir J. 1999 Oct;14(4):902-7.

15. Nathan RA, Sorkness CA, Kosinski M, Schatz M, Li JT, Marcus P, et al Development of the asthma control test: a survey for assessing asthma control. J Allergy Clin Immunol. 2004 Jan;113(1):59-65.

16. Boulet LP, Boulet V, Milot J. How should we quantify asthma control? A proposal. Chest. 2002 Dec;122(6):2217-23.

17. Vollmer WM, Markson LE, O'Connor E, Sanocki LL, Fitterman L, Berger $\mathrm{M}$, et al. Association of asthma control with health care utilization and Quality of Life. Am J Respir Crit Care Med. 1999 Nov;160(5 Pt 1):164752.

18. Thomas M, Kay S, Pike J, Williams A, Rosenzweig JR, Hillyer EV, et al The Asthma Control Test (ACT) as a predictor of GINA guideline-defined asthma control: analysis of a multinational cross-sectional survey. Prim Care Respir J. 2009 Mar;18(1):41-9

19. Nguyen VN, Chavannes N, Le LT, Price D. The Asthma Control Test (ACT) as an alternative tool to Global Initiative for Asthma (GINA) guideline criteria for assessing asthma control in Vietnamese outpatients. Prim Care Respir J. 2012 Mar;21(1):85-9.

20. Juniper EF, Guyatt GH, Cox FM, Ferrie PJ, King DR. Development and validation of the Mini Asthma Quality of Life Questionnaire. Eur Respir J. 1999 Jul;14(1):32-8.

21. Schatz M, Mosen DM, Kosinski M, Vollmer WM, Magid DJ, O'Connor E, et al. Validity of the Asthma Control Test completed at home. Am J Manag Care. 2007 Dec;13(12):661-7.

22. Correia de Sousa J, Pina A, Cruz AM, Quelhas A, Almada-Lobo F, Cabrita J, et al. Asthma control, quality of life, and the role of patient enablement: a cross-sectional observational study. Prim Care Respir J. 2013 Jun;22(2):181-7.

23. Kwon HS, Lee SH, Yang MS, Lee SM, Kim SH, Kim DI, et al. Correlation between the Korean version of Asthma Control Test and health-related quality of life in adult asthmatics. J Korean Med Sci. 2008 Aug;23(4):6217.

24. Zhou X, Ding FM, Lin JT, Yin KS. Validity of asthma control test for asthma control assessment in Chinese primary care settings. Chest. 2009 Apr;135(4):904-10. 